\title{
Dentists mark seventieth anniversary of NHS
}

The seventieth anniversary of the introduction of the NHS in 1948

was marked on 5 July 2018 with a range of national and regional events.

Events including thousands of Big 7Tea events across the country to thank staff and raise awareness of NHS charities took place as well as national celebrations at Westminster Abbey and York Minster to pay tribute to NHS staff and patients.

Around 200 buildings across the country, including the Eden Project in Cornwall, Everton Football Club, the Houses of Parliament and the London Eye, were also illuminated in the NHS's trademark blue to celebrate the anniversary.

NHS Chief Executive Simon Stevens sent a message thanking staff, saying that the NHS's enduring success was down to their 'brilliance'.

In the message, Stevens paid tribute to the achievements of 1.5 million dentists, doctors, nurses, ambulance staff, therapists, porters, caterers and others who, with volunteers and others, made up the biggest care team in the world.

'Today we're marking the seventieth birthday of the National Health Service,' he said. 'It's a time for celebration looking back over seven decades when we're all living a lot longer and healthier - more than 10 years extra.

'We've seen amazing medical advances, whether it's organ transplantations or new cures for cancer or vaccines. But the reason why the health service does so well is frankly due to the brilliance of the staff?.

Support was also provided regionally to NHS organisations and professionals to organise events for staff, patients and other partners.
NHS Digital issued various facts for seven decades tying into NHS seventieth birthday, which included the fact that in $1968,37 \%$ of the population of England and Wales were edentate (had no natural teeth) compared to $6 \%$ in 2009.

Ashkan Pitchforth, a General Dental Practitioner and Clinical Dental Advisor for NHS England South East, said he was happy to be working in the NHS, adding: 'What I enjoy about my role is patient satisfaction. As a dentist you regularly see your patients and develop a very good relationship with them. The patient has gained trust in you and when you are able to improve someone's smile, oral hygiene or relieve their pain then this is very rewarding.

'If I could give the NHS any 70th birthday present, it would be millions of pounds! The NHS does the best it can within the financial constraints from the Government. I feel more money spent within the NHS could result in expansion of services and further improvements.'

Charlotte Waite, Community Dentist in Loughborough said: 'I enjoy meeting the patients and being part of a great team. NHS dentistry is very important especially for patients who can't access care other places.

'We know we almost act as a safety net for certain patient groups and we know that oral health inequalities still exist and we need to be there to support our patients when they need us.'

Ben Underwood, Associate Dentist working in general dental practice in York, said: 'I think it's soul destroying when you see a child with tooth decay and you know that tooth decay was preventable.

'I developed an app - Brush DJ app - because I can see it as a great way to reach people and engage them and improve oral health.'

\section{New dental hospital nears completion}

Staff from the Royal National Throat Nose and Ear Hospital and the Eastman Dental Hospital in London joined contractors recently to celebrate the 'topping out' of the University College London Hospitals NHS Foundation Trust's (UCLH) newest clinical facility, meaning it has reached the highest point of its construction.

Opening next year, the building will bring together the services currently provided at the Royal National Throat Nose and Ear Hospital (RNTENH) and Eastman Dental Hospital (EDH) currently based on the capital's Gray's Inn Road.

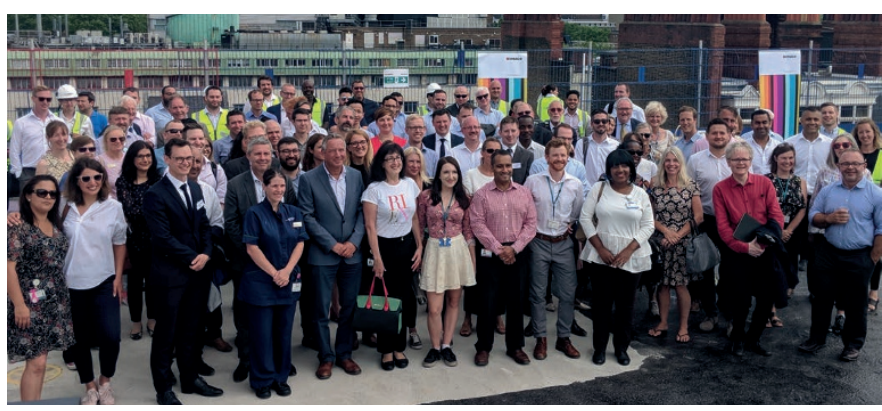

UCLH Chief Executive Marcel Levi and Mace Deputy Chief Operating Officer for Construction Mark Castle, ceremonially completed the highest part of the trust's new hospital on 4 July 2018.

Over the lifetime of the NHS, the two hospitals have been involved in many firsts, such as Eastman Dental Hospital setting up the first clinic for people born with teeth missing.

Levi said: 'The RNTENH and EDH both have fantastic histories. As we celebrate the seventieth birthday of the NHS, I am delighted we are investing $£ 100$ million in this new building for our patients and staff. I look forward to this new facility opening, where we will continue to improve patient care.'

Castle said: 'This is a tremendous milestone for this project, as well as a fitting moment to mark the seventieth anniversary of the NHS. It's a privilege to be able to work with UCLH to deliver a building that will make such a difference to the lives of so many people. I'm very proud of all the work the Mace team have done to get the project to this point.'

The new facility will be called the Royal National ENT and Eastman Dental Hospitals. 